\title{
Characteristics of hydrological extremes in Kulfo River of Southern Ethiopian Rift Valley Basin
}

\author{
Biniyam Yisehak $^{1}$ (D) Kelali Adhena ${ }^{1} \cdot$ Henok Shiferaw ${ }^{1} \cdot$ Haftom Hagos $^{1} \cdot$ Haftu Abrha $^{1} \cdot$ Temesgen Bezabh $^{1}$
}

Received: 9 January 2020 / Accepted: 16 June 2020 / Published online: 30 June 2020

(c) Springer Nature Switzerland AG 2020

\begin{abstract}
Hydrological extreme events such as floods and drought are common in Ethiopia which eventually causes environmental hazards. Kulfo River is one of Southern Ethiopian Rift Valley Basin that has experienced flooding for years. Therefore, this study aimed characteristics of hydrological extremes (1985-2014) in the Kulfo River, which is important for effective drought and flood monitoring and early warning systems. The hydrological drought was assessed using the streamflow drought index (SDI). Flood frequency distribution (FFD) software package was deployed to determine the flood frequency curve of the Kulfo River. The goodness-of-fit test results showed that the Generalized Extreme Values (GEV) distribution was found the best-fit probability distribution model in the Kulfo River, while the results of SDI values showed that extreme drought events were observed in 1991, 1992, and 2014 with magnitudes ranging from -2.04 to $-2.7,-2.0$ to -2.3 , and -2.10 to -2.24 , respectively, which cause reduction of lake level, lowing of groundwater level, and decreased the amount of river flow. SDI value indicated 6-year drought duration has occurred with the relative frequency of $20 \%$ in the 3- and 6-month timescales. The flood frequency results show the lowest probability of having flood magnitude has affected the river morphology. The study provides valuable information for policy and decision makers to implement different adaptation and mitigation measures for extreme hydrological events in the Kulfo River.
\end{abstract}

Keywords Probability distribution model · Hydrological drought · Streamflow drought index · Flood frequency

\section{Introduction}

Flooding in the Southern part of Ethiopia is mostly associated with the geography of the catchment and the natural drainage systems formed by the principal river basins [1, 2]. The extreme rainfall event results in an extreme runoff $[3,4]$ and usually causes a significant damage to the natural system and human-environment [5]. The extreme event frequency analysis and determination of its magnitude at different return periods are important for sustainable water resources management [6-8]. Streamflow drought defines a shortage of water resources, which includes groundwater, reservoir, or streamflow levels. According to A. K. Mishra and V. P. Singh [9], investigation of the past hydrological drought characteristics provides better information for effective monitoring of upcoming drought events.

The best-fit probability distribution model (PDM) for the extreme event study is determined based on goodnessof-fit measures. PDM is most widely used in hydrological extreme events estimation and prediction [1]. Understanding of the characteristics of hydrological extreme events using the best-fit PDM is very important to enhance effective management and utilization of water resources in the catchment $[10,11]$.

Ethiopia is considered as the water tower of the eastern Africa region has frequently experienced hydrological drought at an increasing intensity throughout the past many decades. For instance, the study conducted by Edossa et al. [12] shows an increasing occurrence of

Biniyam Yisehak, b1n1y21@gmail.com | 'Institute of Climate and Society, Mekelle University, 231, Mekelle, Tigray, Ethiopia. 
drought events, with the frequency of drought, occurred within 5 years. The study conducted by Gebrehiwot et al. [13] showed that the frequency of recurrent drought in Ethiopia has been showing an increasing trend for over the past decades. Moreover, flooding in the lower part of Kulfo River catchment becomes an unbeatable disaster and a challenge for the rural community living around the lower catchment. Farmers in the catchment extensively use Kulfo River for their irrigation, but their crops are affected by flooding each year.

Many previous studies have investigated long-term hydrological extreme even related to climate change [14, 15]. Changes in Earth's climate system affect the balance of hydrological cycle and eventually lead to increased occurrence of extreme events such as flood and droughts [16-18]. Recent investigations also show that global climate change will create and intensify more severe frequent floods and droughts in the region $[19,20]$.

Extreme hydrological event analysis is easy to apply, but it includes large uncertainties in the choice of the bestfit probability distribution model, especially when study flood frequency analysis. Moreover, it cannot produce the accurate flood frequency curve for hydraulic structure and it is dependent on the PDMs. Some of the most frequently used PDMs in hydrology are the Gumbel, Generalized Extreme Values Distribution (GEV), Gamma (3P), Log-Normal (2P), Log-Normal (3P) and Log-Pearson (3P) PDMs [21]. However, the choice of an appropriate PDM is still one of the main problems for hydrologist.

To the knowledge of the experts, there was no attempt/ study carried out related to hydrological extreme event analysis using the best-fit PDM in Kulfo River. This research was, therefore, initiated to characterize the hydrological extremes using the best-fit PDM of Kulfo River. The objectives of this study were to conduct (i) the best-fit PDM for determining flood frequency curve (ii) the temporal variation of hydrological drought using at different timescales $(3,6$, and 12 months) and characterize the hydrological droughts, duration, severity, intensity and relative frequency, and finally, analyze the flood frequency curve over return periods of $2,5,10,20,50$, and 100 years.

\section{Materials and methods}

\subsection{Study area}

This study was conducted in Kulfo River Southern Ethiopian Rift Valley Basin, near Arba Minch town with a geographical location between $5^{\circ} 55^{\prime}$ and $6^{\circ} 15^{\prime} \mathrm{N}$ latitude and $37^{\circ}$ $18^{\prime}$ and $37^{\circ} 36^{\prime}$ E longitude, the elevation of between 1253 and $3550 \mathrm{~m}$ above sea level, and has a total area of $492 \mathrm{~km}^{2}$ (Fig. 1). The mean annual temperature rises to $14-23^{\circ} \mathrm{C}$, the catchment receives up to $620-1250 \mathrm{~mm}$ rainfall annually, and the mean annual discharge is estimated at around $1.8-22.8 \mathrm{~m}^{3} / \mathrm{s}$ (for the observation period of 1985-2014). The Kulfo catchment can be classified by four main soil types, namely cambisols, ferralsols, regosols, and fluvisols [22]. It is characterized by severe land degradation resulting in soil erosion, flooding, sediment, and nutrient intrusion to Lake Chamo [23]. In the catchment, agriculture is the major land use activity and occupies the flat alluvial land of the catchment surrounding the river. Thick bushlands, open woodland, forest, grassland with cultivated land are found on the catchment [24]. Extreme flooding events, in and around the catchment, induce restriction on agricultural productivity reduction through the cultivation of nonfarming activities. The Kulfo River also serves as a potential water source for the urban population and covers around $70 \%$ safe water supply to the rural community [25].

\subsection{Data sources}

Thirty-year daily discharge data series for the period of 1985-2014 were collected from Kulfo River station near the town of Arba Minch which were obtained from the Ministry of Water, Irrigation and Energy of Ethiopia (MoWIE) (http://www.mowr.gov.et/). However, in this study, the monthly discharge data analyzed from the above thirtyyear daily discharge data have been used for hydrological drought assessment and annual daily peak-discharge data series were used for flood frequency analysis.

\subsection{Probability distribution models (PDMs)}

The PDM is the integral of the probability density function. This function is very important because it measures the inconsistency among the empirical and theoretical distributions. This is, therefore, for hydrological extreme event analysis the best-fit PDM has been identified as the best method [26].

\subsubsection{Log-Normal (2P)}

The probability density function and cumulative distribution function (cdf) of the 2-parameter Log-Normal (2P) are given as:

$$
\begin{aligned}
& f(x)=\frac{1}{x \sigma \gamma \sqrt{2 \pi}} \exp \left[-\frac{1}{2 \sigma_{\gamma}^{2}}(\ln (x)-\mu \gamma)^{2}\right] \\
& F(x)=\frac{1}{x \sigma \gamma \sqrt{2 \pi}} \int_{0}^{x}\left(\frac{1}{x} \exp \left[-\frac{1}{2 \sigma_{\gamma}^{2}}(\ln (x)-\mu \gamma)^{2}\right]\right) \mathrm{d} x
\end{aligned}
$$



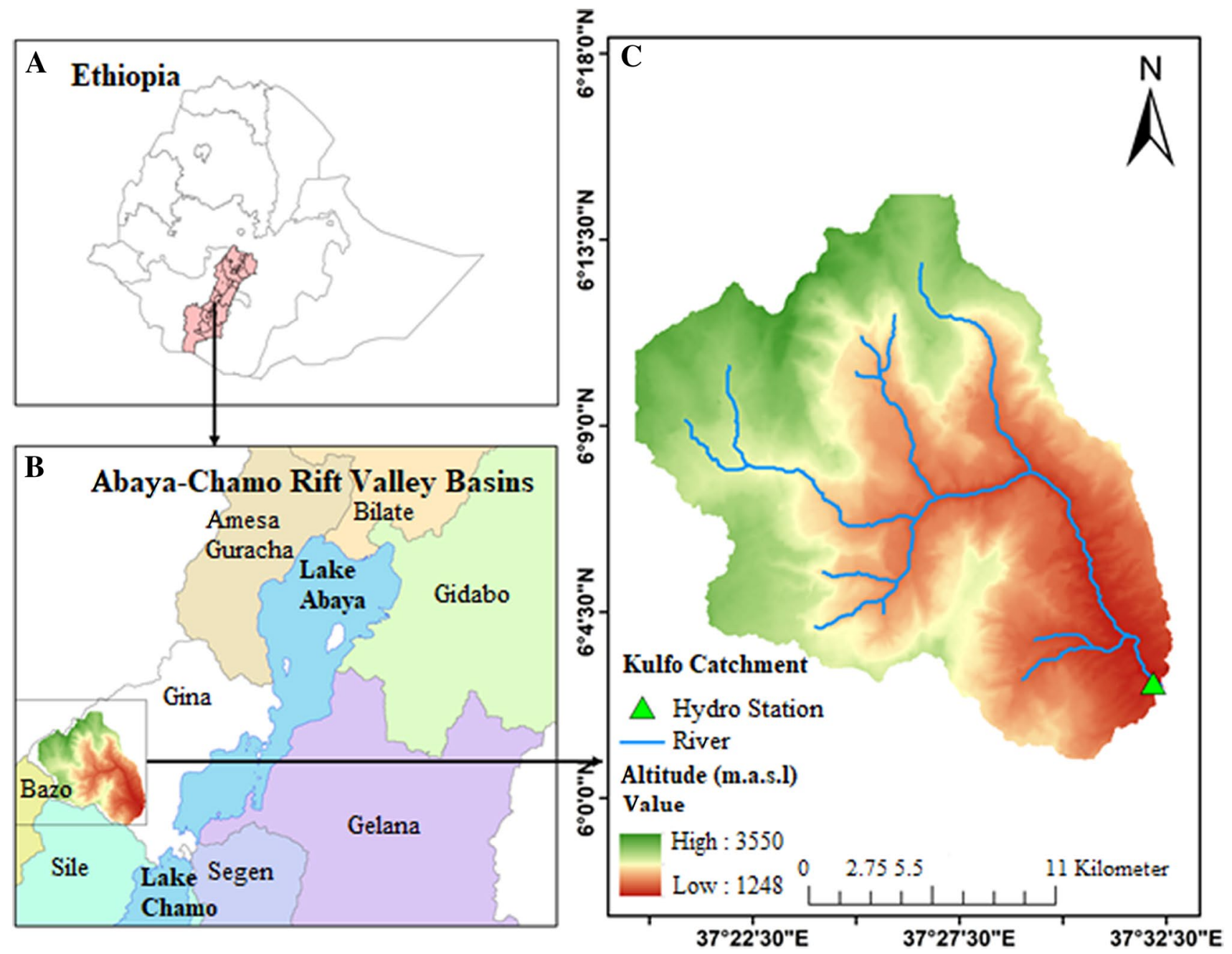

Fig. 1 Regional map of Ethiopia (a), Abay-Chamo Rift Valley Basins watershed map (b), drainage network, hydrological station, and altitude, based on a digital elevation model of Shuttle Radar Topographic Mission $30 \mathrm{~m}$ of study area Kulfo catchment (c)

where the assortment of random variable $x$ is greater than zero. The logarithm of the $x$ variable, $y=\ln (x)$, is best explained by a Normal PDM. Method of momentum (MOM) estimator has been used, and the 2 parameters are expressed as follows:

$\sigma \gamma=\left[\ln \left(1+\frac{\sigma_{X}^{2}}{\mu_{X}^{2}}\right)\right]^{1 / 2}$

$\mu \gamma=\ln (\mu x)-\frac{1}{2} \sigma_{\gamma}^{2}$.

where $\gamma$ is coefficient of skewness, and $X$ is annual daily peak discharge of observed data, which are the commonly used parameters of the Log-Normal (2P) PDM. Here, $\sigma \gamma$ is the standard deviation of coefficient of skewness and $\mu \gamma$ is the mean of coefficient of skewness for the Log-Normal (2P) PDM. The Log-Normal (2P) should be more fitted than the simple Normal PDM as it is appropriate for a "heavy tail" on one side, which can be best-fit annual daily peak discharge of observed data.

\subsubsection{Log-Normal (3P)}

The probability density function of the three-parameter Log-Normal distribution is:

$f(x)=\frac{1}{\left(x-x_{o}\right) \sigma \sqrt{2 \mu}} \exp \left\{-\frac{\left[\ln \left(x-x_{o}\right)-\mu^{2}\right]}{2 \sigma^{2}}\right\}$

where $0 \leq x_{o}<x,-\infty<\pi\langle\infty, \sigma\rangle 0 . \pi, \sigma, a n d x_{o}$ are the parameters of distribution. 


\subsubsection{Gumbel}

Gumbel is extreme value (EV) distributions case, thus extreme value type I corresponds to Gumbel distribution, and the PDM is:

$f(x)=\frac{1}{\alpha} \exp \left[-\frac{x-u}{\alpha}-\exp \left(-\frac{x-u}{\alpha}\right)\right]$

$\alpha=\frac{\sqrt{6} S_{x}}{\pi}$

$u=\bar{x}-0.5772 \alpha$

$a$-Scale and $\mu$-shape are parameters of Gumbel distribution, estimated by L-moment.

\subsubsection{Generalized Extreme Values (GEV)}

The GEV distribution is a family of continuous probability distributions that combines the Gumbel (EV1) and Weibull distributions. GEV distribution makes use of 3 parameters: location $(\xi)$, scale $(\alpha)$, and shape $(k)$ [27]. The parameters are estimated by weighted moments. The probability distribution function is:

$$
\beta=4 / \gamma^{2}
$$

$$
\alpha=\sigma \gamma / 2
$$

$\zeta=\mu-2 \sigma / \gamma$

\subsubsection{Log-Pearson (3P)}

The Log-Pearson (3P), one more Gamma family of PDM, defines a random variable and logarithm following the Log-Pearson type III PDM. The pdf and cdf of Log-Pearson (3P) are as follows:

$$
\begin{aligned}
& f(x)=\frac{1}{\alpha \Gamma(\beta)}\left[\left(\frac{x-}{\alpha}\right)^{\beta-1}\right] \exp \left[-\frac{(\ln (x)-)}{\alpha}\right] \\
& F(x)=\frac{1}{\alpha \Gamma(\beta)} \int^{x}\left[\left(\frac{x-}{\alpha}\right)^{\beta-1}\right] \exp \left[-\frac{(\ln (x)-)}{\alpha}\right] \mathrm{d} x
\end{aligned}
$$

$f_{0, \pi, \sigma}(x)=\frac{1}{\sigma} e^{-(x-\pi) / \sigma} \exp \left(-e^{-(x-\pi) / \sigma}\right) \xi=0$

$k=7.8590 c+2.9554 c^{2}$

where $c=\frac{2}{3+\tau_{3}}-\frac{\ln 2}{\ln 3}, \alpha=\frac{\lambda_{2} k}{\left(1-2^{-k}\right) \Gamma(1+k)}, \xi=\lambda_{1}-\alpha\{1-\Gamma$ $(1+k)\} / k$

\subsubsection{Gamma (3P)}

The other regularly used PDM in extreme event study is the Gamma (3P) PDM which is a 2-parameter Gamma distribution with a third parameter for the location. The pdf and cumulative distribution function of Gamma (3P) are:

$f(x)=\frac{1}{\alpha \Gamma(\beta)}\left[\left(\frac{x-}{\alpha}\right)^{\beta-1}\right] \exp \left[-\frac{(x-)}{\alpha}\right]$

$F(x)=\frac{1}{\alpha \Gamma(\beta)} \int^{x}\left[\left(\frac{x-}{\alpha}\right)^{\beta-1}\right] \exp \left[-\frac{(x-)}{\alpha}\right] \mathrm{d} x$

The parameters are shape $\beta$, scale $\alpha$, and location $\xi$ which are estimated by MOM estimators that are,

\subsection{Goodness-of-fit tests}

Goodness-of-fit test statistics are used to validate a specified or assumed PDM [28], while empirical distribution function tests offer a measure of the inconsistency among the empirical and theoretical distributions. The mostly used empirical distribution function tests are the Kolmogorov-Smirnov (K-S) [29], the Anderson-Darling (A-D) [30], and Chi-squared $(C-S)$ test. The $K-S, A-D$, and $C-S$ tests were applied in this study. The factor of best-fit can also be quantified by using a quantile-quantile (Q-Q) plot. The goodness-of-fit tests were carried out using Easy Fit, available at http://www.mathwave. com/easyfit-distribution-fitting.html.

\subsubsection{Kolmogorov-Smirnov (K-S)}

The Kolmogorov-Smirnov (K-S) test statistic, the highest class of empirical distribution function (EDF) statistics, is based on the highest alteration among the hypothetical and empirical distributions [26]. The main target of this test is to relate the empirical cumulative frequency $\left(S_{n}(x)\right)$ with the cumulative distribution function of an assumed theoretical distribution $\left(F_{X}(x)\right)$ [31]. The highest variance 
among $S_{n}(x)$ and $F_{X}(x)$ is the K-S test statistic. For a model size $n$, the data are reordered in ascending order where $x_{1}<x_{2}<\ldots<x_{n}$ and the $\mathrm{K}-\mathrm{S}$ statistic is evaluated for each value as given:

$S_{n}(x)=0 ; i f X<X_{1}=k / n ; i f X_{k}\left\langle X_{k+1}=1 ; i f X\right\rangle X_{n}$

$D_{n}=\max \left|F_{x}(x)-S_{n}(x)\right|$

$P\left(D_{n} \leq D_{n}^{\alpha}\right)=1-\alpha$

where $D_{n}^{\alpha}$ is the critical value, $\alpha$ is the highest level, and $k$ is the descending order of the data set.

\subsubsection{Anderson-Darling (A-D)}

The Anderson-Darling (A-D) test was first developed by Anderson and Darling [30], and this test is accurate at the tails of the PDM [32]. In belongings with comparatively high extremes, it may be the A-D test to be more appropriate to select the best-fitted PDM to annual daily peakdischarge data [26]. The A-D test statistic, the quadratic class of the EDF test statistic, is explained as $A^{2}$ as follows:

$A^{2}=-\sum_{i=1}^{n}\left[(2 i-1) \ln F_{X}\left(x_{i}\right)+\ln \frac{\left[1-F_{X}\left(x_{n+1-i}\right)\right]}{n}\right]-n$

where $F_{X}\left(x_{i}\right)$ is the cdf of the projected distribution at $x_{i}$, for $i=1,2, \ldots, n$. The annual daily peak-discharge data essentially ordered in ascending order, as $x_{1}<x_{2}<\ldots<x_{n}$.

In the K-S test, both the hypothetical and experimental cumulative distribution functions are comparatively smooth at the tails of the PDMs, which means the A-D test gives more accurate to the tails [32]. This shows a more fitted test when the tails of the selected theoretical distribution are the emphasis of the analysis, as with hydrological events [26].

\subsubsection{Chi-squared (C-S)}

Chi-squared ( $C-S$ ) test is a goodness-of-fit test that relates how the theoretical continuous probability distribution functions fit with the empirical continuous probability distribution functions. The $\mathrm{C}-\mathrm{S}$ test is defined as:

$x^{2}=\sum_{i=1}^{k} \frac{\left(Q_{i}-E_{i}\right)}{E_{i}}$

where $x^{2}$ is the test statistic, $Q_{i}$ is the observed frequency, and $E_{i}$ is the expected frequency defined as:

$E_{1}=F\left(x_{2}\right)-F\left(x_{2}\right)$ where $F$ is the cumulative distribution function (CDF) of theoretical continuous probability distribution functions, and $x_{1}$ and $x_{2}$ are the lower and upper limits.

\subsubsection{Quantile-Quantile (Q-Q) plot}

Quantile-Quantile (Q-Q) plot is an effective method to analyze whether the fitted distributions are reliable with the given set of observations. It is a mean of comparing annual daily peak-discharge data to a theoretical distribution.

The observed data $x_{i}$ are ranked in ascending order and denoted from $x_{1: n}$ to $x_{n: n}$, where $n$ is the total number of observations. A plotting position of the probability $P_{i: n}$ is computed for each $x_{1: n}$ using the plotting position formula defined as:

$P_{i: n}=\frac{(i-0.4)}{(n+0.2)}$

The Q-Q plot, each $x_{1: n}$, is paired with $y_{1: n}$, which is computed from the assumed cumulative distribution function, $F(x)$. The set of points $\left(x_{1: n}, y_{1: n}\right)$ is plotted on normal graph with a $1: 1$ straight line extended from the basis.

\subsection{Drought indices analysis}

\subsubsection{Streamflow drought index (SDI)}

According to Nalbantis and Tsakiris [33], if a time series of monthly discharge $Q_{i, j}$ is available, in which i signifies the water year and $j$ the month within that water year $(j=1$ for October and $j=12$ for September), $v_{j, k}$ can be found based on the equation:

$V i, k=\sum_{j=1}^{3 k} Q i, j i=1,2, j=1,2, \ldots, 12 k=1,2,3,4$

in which $V i, j$ is the overall amount of monthly discharge for the $\mathrm{i}$-th water year and the $\mathrm{k}$-th reference period, $\mathrm{k}=1$ for October-December, $k=2$ for October-March, $k=3$ for October-June, and $\mathrm{k}=4$ for October-September. Based on the overall amount of monthly discharge $V_{i, k}$, the streamflow drought index (SDI) is defined for each reference period $k$ of the $i$-th water year as given:

$S D I_{i, k}=\frac{V_{i, k}-\overline{V_{k}}}{s_{k}} i=1,2, \ldots, k=1,2,3,4$

where $\bar{V}_{k}$ and $s_{k}$ are, respectively, the mean and the standard deviation (SD) of overall amount of monthly discharge of the reference period $\mathrm{k}$ as these are simulated over an extent of time. In this definition the lopping level is set to 
$V_{k}$ although other values based on normal criteria could also be used.

Usually, for small basins, streamflow may follow a skewed probability distribution which can well be approached by the family of the gamma distribution functions, and the SDI index is defined as:

$S D I_{i, k}=\frac{y_{i, k}-\overline{y_{k}}}{s_{y, k}} i=1,2, \ldots, k=1,2,3,4$

in which

$y_{i, k}=\ell n\left(V_{i, k}\right), i=1,2, \ldots, k=1,2,3,4$

are the natural logarithms of overall amount of flow with mean $\bar{y}_{k}$ and standard deviation (SD) $S_{y, k}$ as these statistics are estimated over an extent of time. According to Nalbantis and Tsakiris [33], classes of hydrological drought are explained for SDI in the same way to those used in the standardized precipitation index (SPI) as shown in (Table 1).

\subsubsection{Streamflow drought characteristics}

A drought index is the main variable in order to evaluate the consequence of drought and to decide various drought characteristics, such as length of drought (L), intensity (I), magnitude (M), and relative frequency (RF) [9].

2.5.2.1 Drought duration In order to measure the length of drought (duration) and magnitude of drought (severity), a threshold value must be defined. The drought length $(L)$ is the period length in which the SDI value is continuously negative, started from the SDI values is equal to minus one and ends when the SDI values turn out to be positive.

2.5.2.2 Drought severity The drought severity $(S)$ is the summation of SDI values within the drought duration, which is defined by Eq. (29), and intensity of drought is the ratio of the severity of drought to its duration.

Table 1 Definition of hydrological drought indices (SDI)

\begin{tabular}{lll}
\hline SN & Description & Criterion \\
\hline $\mathbf{1}$ & Nondrought & SDI $\geq 0.0$ \\
$\mathbf{2}$ & Mild drought & $-1.0 \leq \mathrm{SDI}<0.0$ \\
$\mathbf{3}$ & Moderate drought & $-1.5 \leq \mathrm{SDI}<-$ \\
& & 1.0 \\
$\mathbf{4}$ & Severe drought & $-2.0 \leq \mathrm{SDI}<-1.5$ \\
$\mathbf{5}$ & Extreme drought & $\mathrm{SDI}<-2.0$ \\
\hline
\end{tabular}

$S_{i}=-\sum_{i=1}^{D} S D I_{i}$

2.5.2.3 Relative frequency The relative frequency (RF) of drought is the ratio of number of years with drought events (n) (negative SDI) to number of total years (N) [34], and the RF is defined as:

$R F=\frac{n}{N} \times 100$

\subsection{Homogeneity, trend, independence, and stationarity test on annual daily peak discharge}

There are several statistical tests to check the homogeneity, trend, independence, and stationarity of a data series. Some tests are known as parametric because they assume that the analyzed variable is normally distributed. Those that do not make this assumption are called nonparametric tests [35].

In this study, the standard normal homogeneity (SNHT) test for homogeneity [36], Mann-Kendall (M-K) test for trend detection, and Wald-Wolfowitz (W-W) test for independence and stationarity of data $[21,37]$ have been used. The homogeneity, trend, independence, and stationarity test of annual daily peak-discharge data series were carried out in r-programming using trend packages.

\subsection{Flood frequency analysis (FFA)}

The FFA has been carried out for the observed (1985-2014) periods of the annual daily peak-discharge data series were used. It was computed using flood frequency distribution (FFD) package (Run_Flood.m), run using MATLAB software. The Gumbel, Generalized Extreme Values (GEV), Gamma (3P), Log-Normal (2P), Log-Normal (3P), and Log-Pearson (3P) PDMs were used. The FFA has been performed for T-return periods of 2, 5, 10,50, and 100 years. In this study, probability distribution model parameters were determined using the L-moment and method of moments.

\section{Results and discussion}

This study analyzed the characteristics of hydrological extremes in the Kulfo River of Southern Ethiopian Rift Valley Basin. In the catchment, due to heavy rainfall flooding has been a frequent phenomenon where the lower part of the catchment is affected. In preparation for hydrological extreme events, it is important to understand the extreme 
hydrological events such as flood and drought. Hydrological extreme event assessment contains consistent evidence as to the primary factor in the decision-making process [38].

\subsection{Goodness-of-fit tests}

The best-fit distribution was taken as the critical value at alpha 0.05 , for $\mathrm{K}-\mathrm{S}, \mathrm{A}-\mathrm{D}$, and $\mathrm{C}-\mathrm{S}$ tests as shown in Table 2. This value chooses which distribution is accepted or rejected in this study. The result shows all the distributions are statistically accepted. On the other hand, it showed the significance of the distribution. The ranking is given on the difference between statistical and critical value. Among all, the GEV probability distribution model is given the first rank in all three tests. Therefore, Generalized Extreme Values Distribution (GEV) is selected as the bestfit probability distribution model among Gumbel, Gamma (3P), Log-Normal (2P), Log-Normal (3P), and Log-Pearson (3P) probability distribution models.

The quantile-quantile (Q-Q) plot was used to visually examine the level of best-fit probability distribution models. From the visual point of view, there is an insignificant difference to select among the various distributions in the study. The result of the quantile-quantile (Q-Q) plot for the study shows that all distributions are the best-fit with a significant correlation $(R>0.9)$ (Fig. 2). In quantile-quantile $(Q-Q)$ plot theoretically, all points should fall on the 1:1 line if the probability distribution models are the best-fit [39]. In many cases, it is difficult to find out the best-fit one from the visual display of the Q-Q plot. Q-Q plot result shown in (Fig. 2) in all models all points falls in the 1:1 line and significantly correlated. Therefore, in addition to the Q-Q plot further statistical test needs to find out the bestfit probability distribution model.

\subsection{Temporal variations of SDI}

In our study, SDI for 3-, 6-, and 12-month scales are computed to examine the characteristics of hydrological drought in short-, medium-, and long-term period, respectively. The alteration of SDI according to year is shown in Fig. 3. The SDI alteration shows that in the 6 and 12 month timescales exceed the threshold level for extreme dry $(\mathrm{SDI}<-2)$ and extreme wet $(\mathrm{SDI}>2)$. The SDI for the medium and long period values shows that the worst hydrological drought occurred during the hydrological year of 1991, 1992, and 2014 had the most severity indicating extreme drought events, but the 1992 drought event is not observed in the short-term period (3-month drought). However, extreme wet is observed in all timescales. Moreover, it showed that in 1985,1986, 1987, 1990, 1991, 1992, 1993, 1994, 1995, 1999, 2008, 2009, and 2014 hydrological drought events with varying severities occurred during these 30 years. Similarly, the study was conducted by Gebrehiwot et al. [13]; in the Northern Highlands of Ethiopia, severe drought events occurred in the year of 1985, 1987, 1991, and 2009. The Kulfo River has a leading role in the water balance of Lake Chamo as one of Rift Valley Lake in Southern Ethiopia. However, in a recent study, the amount of Lake Chamo water level slowly decreased [40]. This is maybe a result of the above continuously occurred drought events that affect the level of Lake. Therefore, the drought events, combined with the increasing water demand for irrigation and drinking and anthropogenic activates on the catchment, have decreased significantly the amount of water flow to the Lake Chamo.

\subsection{Hydrological drought characteristics}

The hydrological characteristics of drought for $(3,6$, and 12 month) timescales are shown in Tables 3 and 4. Recapitulation has shown the apparent difference in duration, severity, intensity, and relative frequency of each timescale, and it describes the characteristics of drought in a one timescale had a difference with others. The longest drought duration is observed in 3- and 6-month timescales as 6 year (1990-1995), with the relative frequency of $20 \%$. The lowest drought duration is observed in $3-,-6$, and 12-month timescales that are 1 year $(1997,1999,2008$, 2009 , and 2014), with the relative frequency of $3.3 \%$. The percentage of drought occurrence is at three timescales
Table 2 Goodness-of-fit test of the Kulfo River using Kolmogorov-Smirnov (K-S), Anderson-Darling (A-D), and Chi-squared (C-S) test

\begin{tabular}{|c|c|c|c|c|c|c|c|c|c|c|}
\hline \multirow[t]{2}{*}{ SN } & \multirow[t]{2}{*}{ PDMs } & \multicolumn{3}{|c|}{$\begin{array}{l}\text { K-S test (critical value } \alpha \\
\text { at } 0.05=0.2417 \text { ) }\end{array}$} & \multicolumn{3}{|c|}{$\begin{array}{l}\text { A-D test (critical value } \alpha \\
\text { at } 0.05=2.5018 \text { ) }\end{array}$} & \multicolumn{3}{|c|}{$\begin{array}{l}\text { C-S test (critical value } \alpha \\
\text { at } 0.05=9.4877 \text { ) }\end{array}$} \\
\hline & & Statistic & Reject & Rank & Statistic & Reject & Rank & Statistic & Reject & Rank \\
\hline 1 & Log-Normal (2P) & 0.149 & No & 6 & 0.418 & No & 6 & 0.591 & No & 3 \\
\hline 2 & Gumbel & 0.108 & No & 4 & 0.349 & No & 5 & 1.884 & No & 6 \\
\hline 3 & GEV & 0.094 & No & 1 & 0.230 & No & 1 & 0.470 & No & 1 \\
\hline 4 & Gamma (3P) & 0.113 & No & 5 & 0.264 & No & 3 & 0.499 & No & 2 \\
\hline 5 & Log-Pearson (3P) & 0.105 & No & 3 & 0.253 & No & 2 & 0.608 & No & 4 \\
\hline 6 & Log-Normal (3P) & 0.104 & No & 2 & 0.278 & No & 4 & 1.799 & No & 5 \\
\hline
\end{tabular}



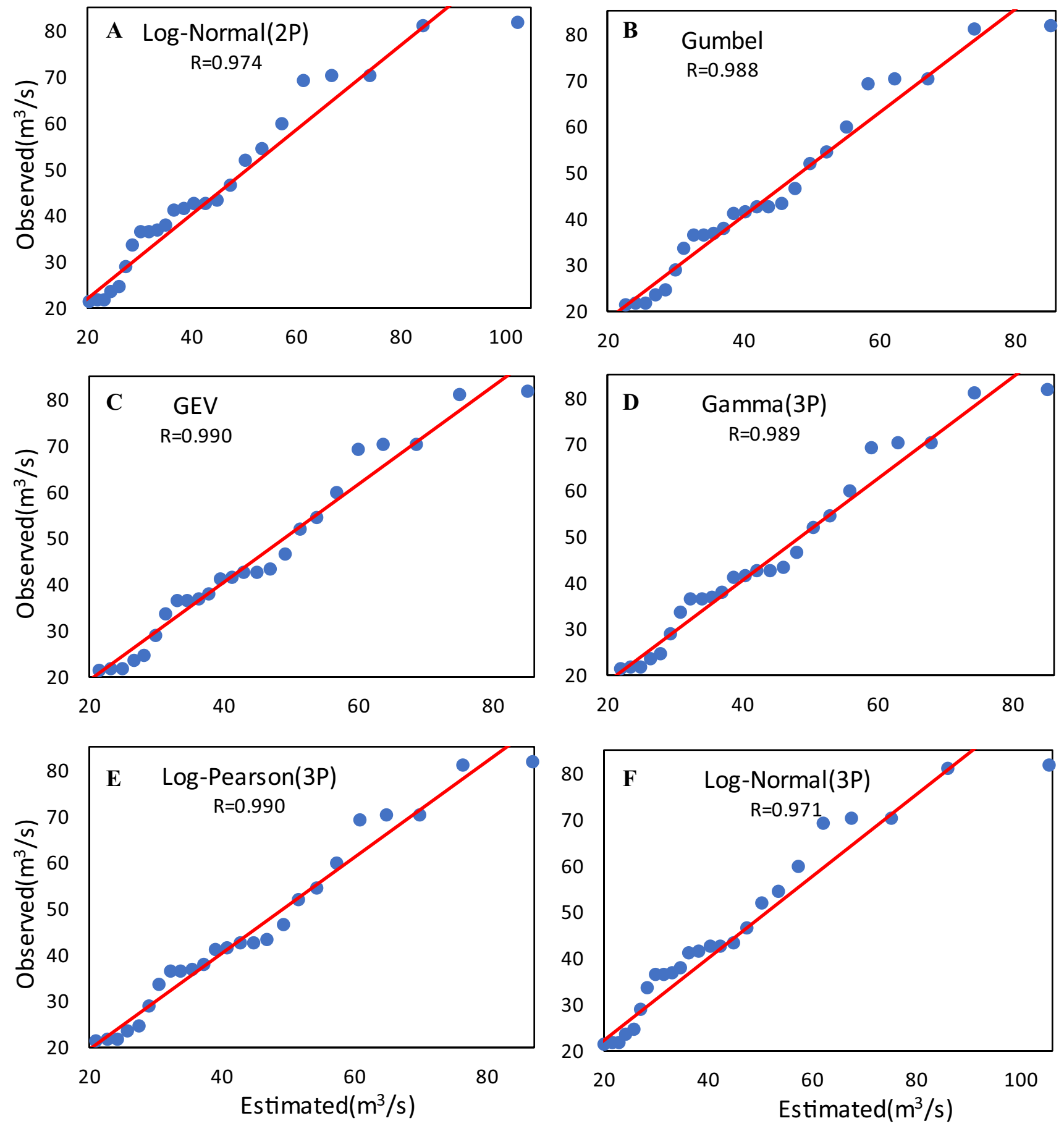

Fig. 2 Quantile-Quantile (Q-Q) plot of annual daily observed vs. estimated peak-discharge data series for Kulfo River (1985-2014), correlation coefficient $(R)$ as the computed $p$ value is greater than the significance level alpha $=0.05$, and the red straight line is $1: 1$ line

and the drought classes in the Kulfo River (Table 4). The result shows that for 3-, -6, and 12-month timescales, mild drought range (57.8-66.7\%) occurs more frequently than expected in the Kulfo River. However, the incidence of drought events severity of mild and above for all timescales has approximately similar values, showing that drought occurs once every $1-3$ years. This result confirmed by previous studies in the Awash River central Ethiopian Rift Valley Basin, for example, around 49\% mild drought occurred most frequently and the basin hits by drought once every 2 years $[12,40]$. 
Fig. 3 Temporal variation of SDI for all set of timescales $(3,6$ and 12 month) in Kulfo River of Southern Ethiopian Rift Valley Basin (1985-2014)

Table 3 Recapitulation of streamflow drought events
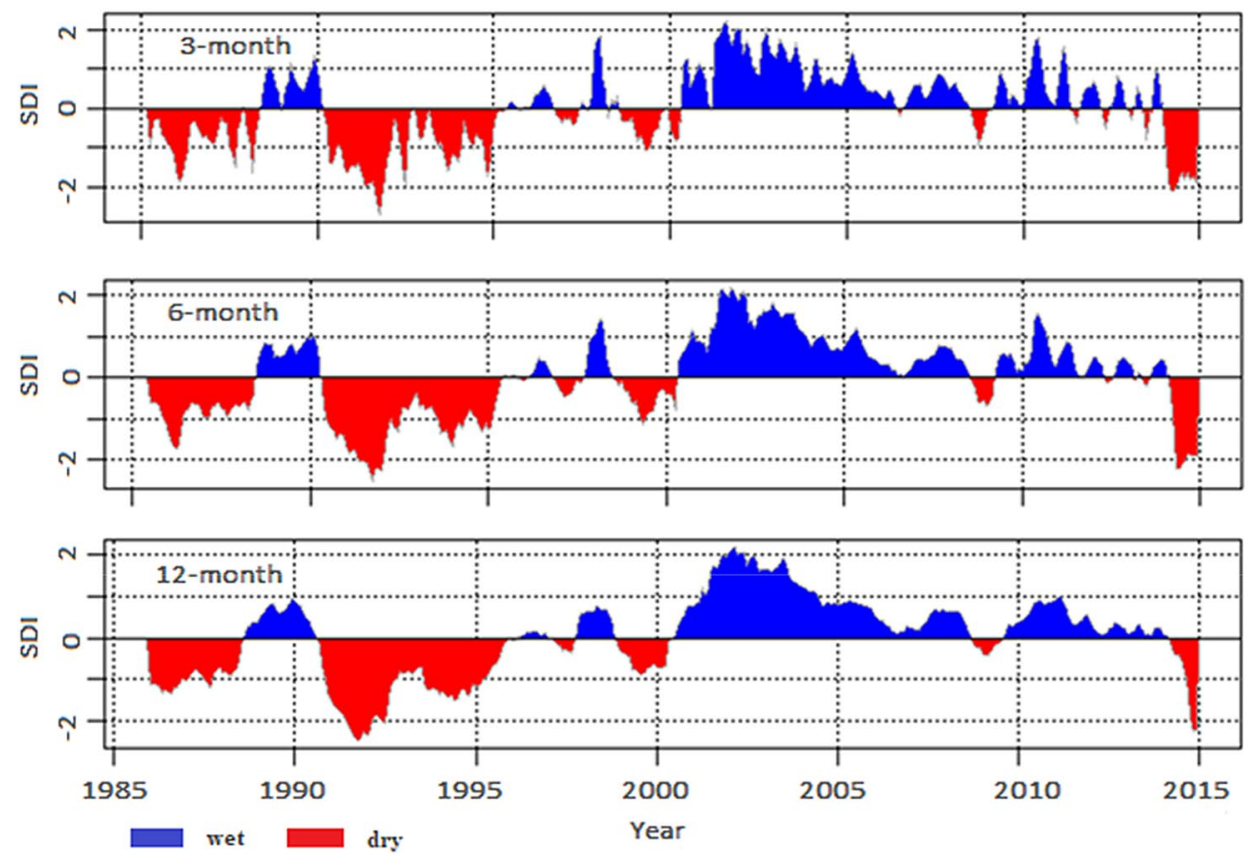

\begin{tabular}{llllllr}
\hline SDI & Onset & Cessation & $\mathrm{L}$ & $\mathrm{M}$ & $\mathrm{I}$ & $\mathrm{RF}(\%)$ \\
\hline 3 month & 1985 & 1987 & 3 & 2.29 & 0.76 & 10.0 \\
& 1990 & 1995 & 6 & 5.53 & 0.92 & 20.0 \\
& 1999 & 1999 & 1 & 0.60 & 0.60 & 3.3 \\
& 2008 & 2008 & 1 & 0.06 & 0.06 & 3.3 \\
6 month & 2014 & 2014 & 1 & 1.76 & 1.76 & 3.3 \\
& 1985 & 1987 & 3 & 2.33 & 0.78 & 10.0 \\
& 1990 & 1995 & 6 & 6.05 & 1.01 & 20.0 \\
& 1997 & 1997 & 1 & 0.03 & 0.03 & 3.3 \\
& 2014 & 2014 & 1 & 1.44 & 1.44 & 3.3 \\
& 1985 & 1988 & 4 & 2.51 & 0.63 & 13.3 \\
& 1991 & 1995 & 5 & 6.66 & 1.33 & 16.7 \\
& 1997 & 1997 & 1 & 0.06 & 0.06 & 3.3 \\
& 1999 & 2000 & 2 & 0.66 & 0.33 & 6.7 \\
& 2009 & 2009 & 1 & 0.07 & 0.07 & 3.3 \\
& 2014 & 2014 & 1 & 0.83 & 0.83 & 3.3 \\
\hline
\end{tabular}

L-length, M-magnitude, I-intensity, RF—relative frequency

\begin{tabular}{lllccc}
\hline SN & SDI range & Drought classification & \multicolumn{3}{l}{ Occurrence (\%) } \\
\cline { 4 - 5 } & & & 3 month & 6 month & 12 month \\
\hline 1 & SDI $<-2.0$ & Extremely dry & 4.2 & 8.2 & 8.2 \\
2 & $-2.0 \leq \mathrm{SDI}<-1.5$ & Severely dry & 14.9 & 7.6 & 6.1 \\
3 & $-1.5 \leq \mathrm{SDI}<-1.0$ & Moderately dry & 14.3 & 20.9 & 27.9 \\
4 & $-1.0 \leq \mathrm{SDI}<0.0$ & Mild dry & 66.7 & 63.9 & 57.8 \\
\hline
\end{tabular}

Table 4 Drought occurrence in Kulfo River for observation period (1985-2014) 
Table 5 Homogeneity, trend detection, independence, and stationarity test of annual daily peak discharge at significance level alpha $=0.05$

\begin{tabular}{|c|c|c|c|c|c|c|c|c|}
\hline \multirow[t]{2}{*}{ Variable (in $\mathrm{m}^{3} / \mathrm{s}$ ) } & \multicolumn{3}{|c|}{ NSHT } & \multicolumn{3}{|l|}{$\mathrm{M}-\mathrm{K}$} & \multicolumn{2}{|c|}{ W-W } \\
\hline & $\mathrm{T}$ & Change point & $p$ value & Sen's slope & tau & $p$ value & Z & $p$ value \\
\hline Peak discharge & 4.14 & 1995 & 0.39 & 0.28 & 0.09 & 0.75 & 3.09 & 0.00 \\
\hline
\end{tabular}
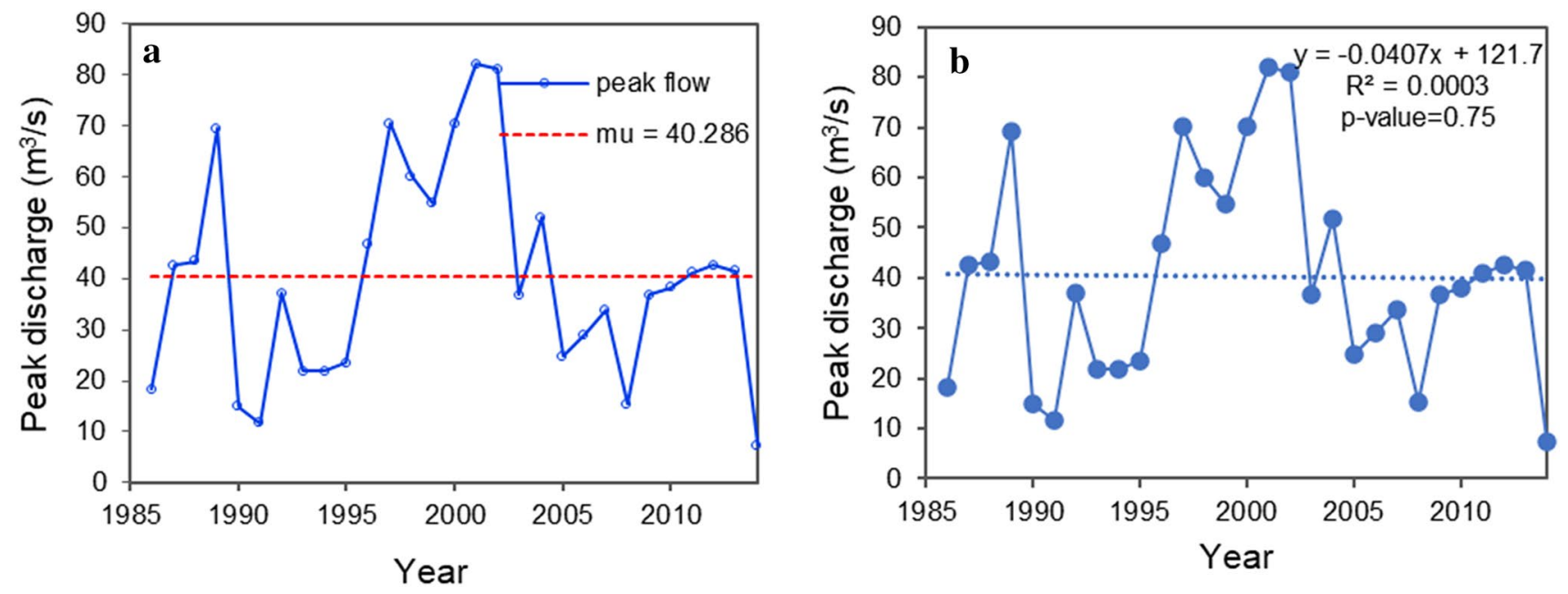

Fig. 4 Change point and trend of annual daily peak discharge of Kulfo River (1985-2014)

\subsection{Homogeneity, trend, independence, and stationarity test of annual daily peak discharge}

For carrying out homogeneity, trend detection, independence, and stationarity analysis, daily annual peakdischarge data series are with the help of the standard normal homogeneity (SNHT) test, Mann-Kendall (M-K) test, and Wald-Wolfowitz (W-W) test, respectively. The test statistic of various tests and acceptance or rejection of the null hypothesis of annual daily peak-discharge data series is presented in Table 5 . The annual daily peak-discharge data series ( $p=0.39)$ show significant $(p>0.05)$ homogenous according to the SNHT test. According to the M-K test, the annual daily peak-discharge data series $(p=0.75)$ show significant $(p>0.05)$ no trend observed. However, the $\mathrm{W}-\mathrm{W}$ test result shows the data series is independent and stationary as the computed $p$ value is lower than the significance level alpha $=0.05$, accept the alternative hypothesis $\mathrm{Ha}$. The time series plot shows there are no significant change point and trend detected (Fig. 4).

\subsection{Flood frequency}

The best-fit probability distribution model of the flood magnitude to return period events is given in Fig. 5 . The result of the best-fit probability distribution model and the

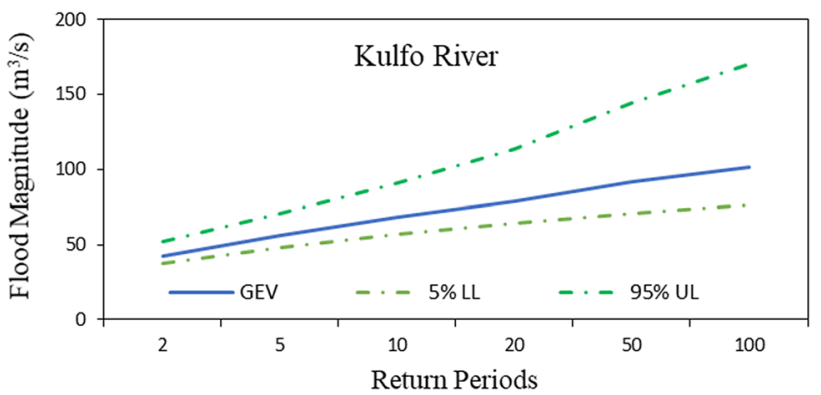

Fig. 5 Flood magnitude and return period of Generalized Extreme Values (GEV) probability distribution model of Kulfo River

flood magnitude for return periods of $2,5,10,20,50$, and 100 years were $42.2,56.1,68,78.7,91.9$, and $101.2 \mathrm{~m}^{3} / \mathrm{s}$, respectively. These flood magnitudes are important in the engineering design of hydraulic structures in the Kulfo River. The 50-year flood event was occurred in the river on an average of every 50 years and had a probability of $2 \%$. The flood magnitude 68.0 and $78.7 \mathrm{~m}^{3} / \mathrm{s}$ would reoccur within the 10- to 20-year return period and had a probability of 5 and $10 \%$, respectively. The highest flood magnitude occurred in 100-year return period which had the lowest probability of occurrence.

The results (Fig. 5) which show the hydrograph of flood magnitude at different return periods are significant in 
their flood risk management and early warning system. Flood causes more loss of life and distraction than any other natural event. The study conducted by Council [41] concludes that distraction from floods in many countries is increasing over time. The frequency and intensity of extreme hydrological events are changing in ways that are difficult to understand and predict.

\section{Conclusion}

Based on the Kolmogorov-Smirnov (K-S), Anderson-Darling $(A-D)$, and Chi-square $(C-S)$ test result among six probability distribution models (Log-Normal (2P), Gumbel, Generalized Extreme Values (GEV), Gamma (3P), Log-Pearson (3P), and Log-Normal (3P)), the Generalized Extreme Values (GEV) were found the best-fit probability distribution model in the Kulfo River.

The hydrological drought characteristics in the region showed an apparent change in all timescale; the extended drought duration is observed in 3- and 6-month timescales 6 years (1990-1995), with the relative frequency of $20 \%$. This, in turn, delivers an indication for proper policy enforcement to safeguard and control drought-associated risks in the study area.

The 50-year return period of flood indicates increment in flood events of 10- and 20-year return periods. This will have significant impacts on the community and the river's morphology. Therefore, the government authorities in the basin need to inform the community hydrological risks to create consciousness and work on flood control projects. The information should include best management practices such as flood and drought protection and early warning systems.

The flood frequency studies can be used in the application of hydraulic structures and the delineation of regulatory floodplains, and also, substantially the return period of these hydrological events can be used in understanding the risk level of damage by extreme flood events, while for the expansion of a long-term regional water plan and the readiness for drought in the region, the current information of drought characteristics is important.

Hydrological drought analyses based on one indicator may not be enough because drought singularities are related to multiple variables (e.g., rainfall, river discharge, and soil moisture).

Acknowledgements The author gratefully acknowledges National Meteorological Agency of Ethiopia (NMA) and Ministry of Water, Irrigation and Energy of Ethiopia (MoWIE) for their all-rounded support and cooperation in availing the necessary data free of charge for this study.
Availability of data and material Data will be made available on request.

\section{Compliance with ethical standard}

Conflict of interest The authors declare no conflict of interest.

\section{References}

1. Robi MA, Abebe A, Pingale SM (2019) Flood hazard mapping under a climate change scenario in a Ribb catchment of Blue Nile River basin, Ethiopia. Appl Geomat 11(2):147-160. https:// doi.org/10.1007/s12518-018-0249-8

2. Erena SH, Worku H (2018) Flood risk analysis: causes and landscape based mitigation strategies in Dire Dawa city, Ethiopia. Geoenviron Disasters 5(1):16. https://doi.org/10.1186/s4067 7-018-0110-8

3. Gaume E, Livet M, Desbordes M, Villeneuve J-P (2004) Hydrological analysis of the river Aude, France, flash flood on 12 and 13 November 1999. J Hydrol 286(1-4):135-154. https://doi. org/10.1016/j.jhydrol.2003.09.015

4. Knapp AK et al (2008) Consequences of more extreme precipitation regimes for terrestrial ecosystems. Bioscience 58(9):811821. https://doi.org/10.1641/B580908

5. Khan AN (2011) Analysis of flood causes and associated socioeconomic damages in the Hindukush region. Nat Hazards 59(3):1239. https://doi.org/10.1007/s11069-011-9830-8

6. Madsen H, Pearson CP, Rosbjerg D (1997) Comparison of annual maximum series and partial duration series methods for modeling extreme hydrologic events: 2 . Regional modeling. Water Resour Res 33(4):759-769. https://doi.org/10.1029/96WR03849

7. Machado MJ, Benito G, Barriendos M, Rodrigo FS (2011) 500 years of rainfall variability and extreme hydrological events in southeastern Spain drylands. J Arid Environ 75(12):1244-1253. https://doi.org/10.1016/j.jaridenv.2011.02.002

8. Leščešen I, Dolinaj D (2019) Regional flood frequency analysis of the pannonian basin. Water 11(2):193. https://doi.org/10.3390/ w11020193

9. Mishra AK, Singh VP (2010) A review of drought concepts. J Hydrol 391(1-2):202-216. https://doi.org/10.1016/j.jhydr ol.2010.07.012

10. Koutsoyiannis D, Montanari A, Lins HF, Cohn TA (2009) Climate, hydrology and freshwater: towards an interactive incorporation of hydrological experience into climate research. Hydrol Sci J. https://doi.org/10.1623/hysj.54.2.394

11. Zwiers FW et al (2013) Climate extremes: challenges in estimating and understanding recent changes in the frequency and intensity of extreme climate and weather events. In: Asrar G, Hurrell J (eds) Climate science for serving society. Springer, Berlin, pp 339-389

12. Edossa DC, Babel MS, Das Gupta A (2010) Drought analysis in the Awash river basin, Ethiopia. Water Resour Manag 24(7):14411460. https://doi.org/10.1007/s11269-009-9508-0

13. Gebrehiwot T, van der Veen A, Maathuis B (2011) Spatial and temporal assessment of drought in the Northern highlands of Ethiopia. Int J Appl Earth Obs Geoinf 13(3):309-321. https://doi. org/10.1016/j.jag.2010.12.002

14. Xu ZX, Takeuchi K, Ishidaira H, Li JY (2005) Long-term trend analysis for precipitation in Asian Pacific FRIEND river basins. Hydrol Process An Int J 19(18):3517-3532. https://doi.org/10.1002/ hyp.5846 
15. Ryu JH, Kim J (2019) A study on climate-driven flash flood risks in the boise river watershed, Idaho. Water 11(5):1039. https:// doi.org/10.3390/w11051039

16. Rosenzweig C, Iglesias A, Yang X-B, Epstein PR, Chivian E (2001) Climate change and extreme weather events; implications for food production, plant diseases, and pests. Glob Chang Hum Heal 2(2):90-104

17. Van Aalst MK (2006) The impacts of climate change on the risk of natural disasters. Disasters 30(1):5-18. https://doi.org/10.11 $11 /$ j.1467-9523.2006.00303.x

18. Sheffield J, Wood EF (2007) Characteristics of global and regional drought, 1950-2000: analysis of soil moisture data from off-line simulation of the terrestrial hydrologic cycle. J Geophys Res Atmos. https://doi.org/10.1029/2006JD008288

19. Erwin KL (2009) Wetlands and global climate change: the role of wetland restoration in a changing world. Wetl Ecol Manag 17(1):71. https://doi.org/10.1007/s11273-008-9119-1

20. Birhanu D, Kim H, Jang C, Park S (2016) Flood risk and vulnerability of Addis Ababa city due to climate change and urbanization. Procedia Eng 154:696-702. https://doi.org/10.1016/j.proen g.2016.07.571

21. Hamed K, Rao AR (2019) Flood frequency analysis. CRC Press, Boca Raton

22. F. and A. O. of the U. N. L. and W. D. Division, the soil and terrain database for Northeastern Africa: crop production system zones of the IGAD subregion. FAO, 1998

23. Blumberg S, Schütt B (2004) Character of lake floor sediments from central Lake Abaya, South Ethiopia. In: Lake Abaya research symposium 2004-proceedings, vol. 4, pp 1-10

24. WoldeYohannes A, Cotter M, Kelboro G, Dessalegn W (2018) Land use and land cover changes and their effects on the landscape of Abaya-Chamo Basin, Southern Ethiopia. Land MDPI Open Access J 7(1):1-17

25. Teklemariam A (2005) Water quality monitoring in Lake Abaya and Lake Chamo Region: a research based on water resources of the Abaya-Chamo basin-South Ethiopia. Verlag nicht ermittelbar

26. Alam MA, Emura K, Farnham C, Yuan J (2018) Best-Fit probability distributions and return periods for maximum monthly rainfall in Bangladesh. Climate 6(1):9. https://doi.org/10.3390/cli60 10009

27. Salinas JL, Castellarin A, Kohnova S, Kjeldsen TR (2014) Regional parent flood frequency distributions in Europe-Part 2: climate and scale controls. Hydrol Earth Syst Sci 18(11):4391-4401. https ://doi.org/10.5194/hess-18-4391-2014

28. Hosmer DW, Lemesbow S (1980) Goodness of fit tests for the multiple logistic regression model. Commun Stat Methods 9(10):1043-1069. https://doi.org/10.1080/03610928008827941

29. Smirnov N (1948) Table for estimating the goodness of fit of empirical distributions. Ann Math Stat 19(2):279-281
30. Anderson TW, Darling DA (1954) A test of goodness of fit. J Am Stat Assoc 49(268):765-769

31. Beguería S, Angulo-Martínez M, Vicente-Serrano SM, LópezMoreno Jl, El-Kenawy A (2011) Assessing trends in extreme precipitation events intensity and magnitude using non-stationary peaks-over-threshold analysis: a case study in northeast Spain from 1930 to 2006. Int J Climatol 31(14):2102-2114. https://doi. org/10.1002/joc. 2218

32. Farrell PJ, Rogers-Stewart K (2006) Comprehensive study of tests for normality and symmetry: extending the Spiegelhalter test. J Stat Comput Simul 76(9):803-816

33. Nalbantis I, Tsakiris G (2009) Assessment of hydrological drought revisited. Water Resour Manag 23(5):881-897. https://doi. org/10.1007/s11269-008-9305-1

34. Saravi MM, Safdari AA, Malekian A (2009) Intensity-durationfrequency and spatial analysis of droughts using the standardized precipitation index. Hydrol Earth Syst Sci Discuss 6(2):13471383. https://doi.org/10.5194/hessd-6-1347-2009

35. García-Marín AP, Estévez J, Morbidelli R, Saltalippi C, AyusoMuñoz JL, Flammini A (2020) Assessing inhomogeneities in extreme annual rainfall data series by multifractal approach. Water 12(4):1030. https://doi.org/10.3390/w12041030

36. Alexandersson $\mathrm{H}$ (1986) A homogeneity test applied to precipitation data. J Climatol 6(6):661-675. https://doi.org/10.1002/ joc.3370060607

37. WMO (2009) Guide to hydrological practices, volume II: Management of water resources and application of hydrological practices. World Meteorological Organization Geneva, Switzerland

38. Wilhite DA, Sivakumar MVK, Wood DA (2000) Early warning systems for drought preparedness and drought management. In: Proceedings of an expert group meeting held in Lisbon, Portugal, vol 57

39. Tao D, Nguyen V-T-V, Bourque A (2002) On selection of probability distributions for representing extreme precipitations in Southern Quebec. In: Annual conference of the Canadian society for civil engineering, pp 1-8

40. Bewketu K (2010) Hydrodynamics of selected ethiopian Rift Lakes. Unpubl. M. Sc thesis, Addis Ababa Univ. Ethiop. http://etd. aau.edu.et/dspace/bitstream/123456789/2767/1/Kassaye\%20 Bewketu.pdf. Accessed June 2010

41. Council NR (2000) Risk analysis and uncertainty in flood damage reduction studies. National Academies Press, Washington

Publisher's Note Springer Nature remains neutral with regard to jurisdictional claims in published maps and institutional affiliations. 